\title{
Subversión de la figura del mártir en la narrativa chilena contemporánea
}

For a subversion of the martyr's figure in the contemporaneous Chilean narrative

\author{
Claire Mercier
}

Universidad de Chile, Facultad de Filosofía y Humanidades, Departamento de Literatura. Santiago, Chile. Correo electrónico: claire-mercier@live.fr

El estudio se acerca a la subversión de la figura tradicional del mártir en la narrativa chilena contemporánea, a partir del análisis de dos novelas: El Desierto de Carlos Franz (2005) y La vida doble de Arturo Fontaine (2010). Se inscriben su trama durante el periodo de la Dictadura Chilena y a través del camino identitario de dos mujeres. Así, se tratará de seguir una huella ambigua y torturada respecto a una inversión de la figura del mártir "convencional", a fin de esbozar los contornos de su recreación por la literatura (y para qué).

Palabras clave: subversión, mártir, identidad femenina, Dictadura Chilena, narrativa chilena contemporánea.

The study approximates itself to the subversion of the martyr's figure in the contemporaneous Chilean narrative, based on the analysis of two novels: El Desierto by Carlos Franz (2005) and La vida doble by Arturo Fontaine (2010). The history takes places during the Military Dictatorship and presents the identity development of two women. The aim is to follow the ambiguous and tortured track of the two women, conjointly with an inversion of the figure of the "conventional" martyr, with the final goal to draw the outlines of its recreation in the literature (and what for).

Key words: subversion, martyr, female identity, Chilean Dictatorship, contemporaneous Chilean novel.

\section{INTRODUCCIÓN}

¿Y si existiera una manera de sobrepasar el dolor aceptándolo? ¿Y si un castigo pudiera devolver a la carne su irreductibilidad? ¿Y si pudiera ser bastante humillador como para restituirla a su primera integridad? ¿Podemos, de verdad, concebir un sufrimiento acercándonos a la vez al amor y a la muerte? Una huella de devoción parece aceptar el camino ineluctable del Mal: el mártir.

Lo acepta y aun, lo solicita, al interior de una apuesta sin límites. No obstante, siguiendo el camino todavía más lejos: ¿no sufre respecto a un privilegio? En efecto, el mártir es esta figura que se somete a una voluntad exterior, a un orden que le sobrepasa y a quien quiere ofrecer su sumisión, su dolor, a cambio de un amor 
infinito, a la imagen de su fervor. Este mismo movimiento de trascendencia de sí mismo, se sitúa además al interior del Mal (aceptando el sufrimiento) y a la vez en contra de él, ya que se establece en oposición a su orden: el mártir es una figura de resistencia y de subversión de la autoridad imperiosa. En este sentido, se define como popular (a partir de un movimiento de rechazo proviniendo de abajo) y como símbolo de una minoría sufrida. A diferencia de la víctima, no le importa al mártir sobrevivir y su consagración se constituirá mediante un sacrificio sin compromiso. ¿Podría ser concebido como un herético? Este último se constituye más como mártir a causa de la persecución del pueblo en general y no en contra de una autoridad omnipotente. En efecto, parece que la autoridad busca imponerse, establecerse como tal, mediante la figura del mártir, considerándolo entonces como el elemento perturbador a eliminar. Aquí, la figura del mártir se une a la del chivo expiatorio, a través de un sacrificio personal destinado a limpiar el pecado $^{1}$ de la conciencia colectiva y a establecer de nuevo la autoridad como tal.

Para resumir, el mártir es ante todo el que sufre respecto a un ideal que le sobrepasa: “[...] la palabra "mártir", confiriéndole su primer y más corriente sentido, no de testimonio sino de suplicio. La palabra dirigida al otro, no la palabra pecadora sino el discurso de fe, es un dolor: esto es lo que sitúa al acto de la comunicación verdadera, el acto de testimonio, en el registro de la persecución y de la victimización" (Kristeva 1988: 172).

Es también, según la etimología griega, el testigo: "El testigo es capaz de sufrir y morir por lo que cree. Cuando la prueba de la convicción llega a ser el precio de la vida, el testigo cambia de nombre: se llama mártir [...] en griego, quiere decir testigo" (Ricoeur 1983: 21).

No obstante, más concretamente, ¿quiénes son los mártires de hoy? Como lo dijimos, el mártir se diferencia de la víctima, pero también del héroe, figura colectiva mítica, luchando en la luz del triunfo. El mártir, por su parte, detiene y sigue una huella diferente, en la obscuridad del Mal y en la solitud del dolor.

En un nivel estético, el mártir es un topos recurrente, tanto en pintura como en literatura ${ }^{2}$. Sin embargo y lógicamente, se constituye esencialmente como un tema cristiano y pertenece a un otro plano temporal. En efecto, hoy no encontramos con frecuencia el relato "verídico" del mártir de un hombre y, por ejemplo, su beatificación por la Iglesia católica. Es que el mártir se adaptó a una sociedad más "laica". En efecto, el mártir se convirtió en el símbolo de todos los hombres luchando por un ideal, al interior de la tortura física, como por ejemplo, los resistentes durante el periodo de la Segunda Guerra Mundial. Así, el mártir opera su reconversión y no deja de estar presente en la Historia y entonces, en la producción estética.

Para seguir nuestra huella analítica, decidimos restringir el campo de las manifestaciones estéticas contemporáneas de la figura del mártir, a dos novelas que inscriben su trama durante el periodo de la Dictadura Chilena y a través del camino identitario de dos mujeres. La primera es El Desierto de Carlos Franz (2005). Laura, una jueza instalada en un pueblo del desierto chileno, es entregada a los

\footnotetext{
"En el registro de la deuda y de la iniquidad, más aun que en el de la impureza, el pecado se enuncia como constitutivo del hombre" (Kristeva 1988: 161).

2 Ver el ejemplo del Albrecht Dürer y del Martirio de los diez mil cristianos y el ejemplo de La Tentation de Saint Antoine de Gustave Flaubert, respectivamente.
} 
militares (sobre todo al Mayor Cáceres) por los mismos habitantes de su ciudad, a fin de detener las ejecuciones. Se va a crear una especie de relación amorosa con su torturador/salvador, hasta tener una hija con él. La segunda es La vida doble de Arturo Fontaine (2010). La protagonista principal (Irene y/o Lorena) es una activista de una organización revolucionaria, entonces, en contra de la "autoridad" establecida por los militares. Después de su detención y de su tortura, va a colaborar, pero aceptando el sufrimiento y su nueva condición hasta enamorarse de su torturador (o sea del Mal, transformándolo en una forma de salvación, confundiendo entonces los papeles de verdugo y de salvador).

Lo que nos interesa es que la figura del mártir en estas dos novelas, en estas dos “leyendas negras", según la expresión de Diamela Eltit (1996: 102), no es claramente dada como tal, es decir que no se trata de un resistente muriendo por sus ideales. En efecto, lo que estamos apostando es seguir una huella ambigua y torturada, a partir de una inversión de la figura del mártir "convencional", a fin de esbozar los contornos de su recreación por la literatura (y para qué).

En efecto, primero, las dos novelas de nuestro corpus de análisis invierten la figura del mártir como que el que sufre, mediante los fenómenos del sado-masoquismo y/o del síndrome de Estocolmo. A continuación, las obras parecen crear un nuevo tipo de mártir, respecto a una desviación del mártir como testigo. Finalmente, sería cuestión de considerar la apertura de los posibles emprendida por esta nueva huella.

\section{DE LA INVERSIÓN: LA FIGURA DEL MÁRTIR COMO EL QUE SUFRE}

Una de las primeras aceptaciones del término "mártir" es en referencia a una persona a la que se infligió suplicios físicos y mentales. Yendo más allá, es también una persona que acepta el sufrimiento en vez de abjurar, en el caso del mártir cristiano, su fe. En efecto, el mártir soporta el dolor a partir de la promesa de un destino mejor (en el caso una vez más del mártir cristiano, de una entrada garantizada en el Paraíso).

En nuestro corpus de análisis, podemos definir las dos protagonistas de los dos relatos como mártires, debido a que las dos se posicionan como aceptando el sufrimiento (en este caso, la tortura de los militares). Sin embargo, en este contexto, la figura se acerca más a la concepción moderna de la figura de mártir, o sea, del mártir político, soportando la tortura de la autoridad en vez de delatar a sus compañeros o, más generalmente, en vez de traicionar el ideal por el cual se lucha.

No obstante, interviene en las dos novelas, un fenómeno de inversión de la figura del mártir como el que sufre, a través de la relación torturador/víctima y en relación con el fenómeno del sado-masoquismo ${ }^{3}$ y/o del síndrome de Estocolmo ${ }^{4}$. En efecto, en este caso, el mártir acepta y recurre al dolor físico como fuente de placer. Entonces,

\footnotetext{
"Le masochiste [...] désire que cette douleur soit infligée par amour" (243); “[...] le sadiste [...] il désire que cette douleur soit ressentie comme de l'amour" (243-244) (Havelock 1921).

4 Si lo consideramos como una forma peculiar de la relación sado-masoquista, en el sentido de una relación de empatía o de identificación de una víctima por su victimario: "El "Síndrome de Estocolmo" es la fusión de la erótica y de la política perversa: la fascinación en la violación, el ansia de destrucción y el apetito de vida, el encanto de la aniquilación, de la autoaniquilación, pero no de la muerte sin vuelta" (Devés 1996: 105-106).
} 
a diferencia de la víctima que quiere vivir, las dos protagonistas sobrepasan esta perspectiva, respecto a una relación de amor con su verdugo.

Primero, en La vida doble, más allá del estado de la víctima que quiere sobrevivir, la protagonista acepta el sufrimiento inherente a su "condición", hasta enamorarse de su torturador: “¿Me creerías si te dijera que más de alguna salía de su calabozo de noche a bailar y a besarse con sus carceleros en alguna discoteca y que eso fue parte del horror?" (148).

Este proceso llega incluso hacia una remodelación de su propio ser, una redefinición identitaria:

Aunque me costará reconocerlo, yo me había empezado a enamorar del Flaco [...]. Fui una amante sumisa, como si mi sumisión me permitiera participar de su poder. Sentí que sus manos al tocarme me hacían de nuevo, como si mi carne fuera greda fresca, esa vieja imagen que mi "yo" feminista odiaba y creía haber superado. Mi humillación me había deshecho y sólo un ser humano podía recrearme [...]. Pero yo sabía que él podía matarme con esas mismas manos, con un solo golpe silencioso. Eso me daba miedo. Él sabría cómo hacer desaparecer toda evidencia. Me recorría una excitación ligera y peligrosa (160).

Sin embargo, la misma relación llega también hacia una inversión, sobre el modelo de la dialéctica del amo y del esclavo de Hegel (2000[1807]), con el esclavo convirtiéndose en un amo respecto a la emergencia de una conciencia sádica del propio mártir, que se convierte pues en un verdugo, reconociendo que: "Hay un placer tiránico en la degradación de uno mismo" (Fontaine 2010: 226).

Pero, la relación esclavo/amo puede ser concebida de un modo más sutil e incluso más hermoso, como con Bourdieu y su "acto de libre alienación indefinidamente afirmado", o sea, la base del contrato sado-masoquista, con el sujeto amoroso (ya que se trata también de amor) que:

Entrega libremente su libertad a un dueño que le entrega también la suya propia, coincidiendo con él en un acto de libre alienación indefinidamente afirmado [...]. Se siente como un creador casi divino que crea, ex nihilo, la persona amada a través del poder que ésta le concede (especialmente el poder de dominación, manifestado en todos los hombres únicos y conocidos exclusivamente por ellos que se dan mutuamente los enamorados y que, al igual que en un ritual iniciático, marcan un nuevo nacimiento, un primer comienzo absoluto, un cambio de estatuto ontológico); pero un creador que, a cambio y simultáneamente, se vive a sí mismo, a diferencia de un Pigmalión egocéntrico y dominador, como la criatura de su criatura (2000: 136).

En El Desierto, la protagonista no define su relación como amorosa, sino más bien como una relación de complicidad, de intimidad:

Ya que lo que hubo entre ambos, entre el verdugo y la víctima, merecía otra palabra, impronunciable y sin embargo necesaria, lo que hubo no fue primero "culpabilidad", sino que antes fue "intimidad". Tal había sido su intimidad que, en ella, Laura había encarnado la norma, la regla, el canto de acero del otro. Y con esa norma, con esa regla, había sido medida, y su medida había sido la traición. Y en esa traición, a su turno, había consistido su intimidad. Éste era el misterio inefable, inexplicable (450). 
Además, esta "intimidad" siempre es descrita en la novela respecto a las dos figuras del Nacimiento de la Tragedia de Nietzsche, es decir Apolo y Dionisio, recobrando la diferencia entre Eros y Tánatos, o sea, entre el deseo de amor y, a la vez, de muerte ${ }^{5}$, los dos extremos de la relación sado-masoquista. Esto plantea también, en relación con la referencia a Nietzsche, la visión del contexto de la Dictadura Chilena como la de una tragedia, estableciendo un lazo y una problematización entre la perspectiva existencial y estética de una catástrofe.

Además, la protagonista concibe al verdugo como un padre, un salvador e incluso un dios. Es decir que la autoridad, haciendo sufrir al mártir y la fe en general que debería salvarlo, confunde e invierte la relación mártir/verdugo, a partir de la relación sado-masoquista.

En La vida doble, por ejemplo, tenemos la figura del dios inclemente, a la manera del Libro de Job ${ }^{6}$ :

Me sorprendo sin querer buscando la falta en mí. Es un dios implacable pero justiciero, cuya ira he de haber desatado yo. Se instalará así la culpa con ella, la voluntad de sacrificarle algo como expiación. Brotará la atracción por colaborar con él. Es el miedo, por supuesto, pero un miedo transfigurado en remordimiento. El padre omnipotente no puede ser tan malo, debería ser posible redimir mi pecado (143).

En El Desierto, tenemos la misma comparación con Dios: “Cáceres me habló. La voz me llegaba desde arriba, tan alta y ausente que parecía caer desde el cielo mismo. Como si me hablara Dios padre" (243). ${ }^{7}$

Se encuentra también esta confusión entre el torturado y el salvador, entre el mártir dispuesto a sufrir por su dios y la promesa de su salvación después de la muerte:

El cuerpo de mi verdugo era, paradójicamente, esa tabla de salvación en el naufragio del desierto [...]. Mi verdugo era la única defensa que me quedaba contra su misma violencia, la única compañía en esa perfecta soledad. Y sin comprenderlo supe que ese orgasmo negro era la forma primordial del agradecimiento que él me había predicho: estaba viva en medio de la muerte gracias a que me aferraba a la propia muerte. En medio de sus lágrimas, la Patrona sonreía (Franz 2005: 269).

Como lo dijimos, los fenómenos del sado-masoquismo y/o del síndrome de Estocolmo, invierten la imagen tradicional del mártir como el que sufre, con las dos protagonistas aceptando el sufrimiento, pero yendo más allá, creando una relación de intimidad y/o de amor con su verdugo, considerándolo entonces como su propia posibilidad de redención. Es en este sentido que Bataille, en Les Larmes d'Éros, sostiene una relación de naturaleza entre el erotismo, el éxtasis religioso y el sadismo:

\footnotetext{
"La peculiar mezcla de emociones en el corazón del festejante dionisíaco -su ambigüedad-parece remontarse (como la droga medicinal se remonta al veneno mortal) a los días cuando infligir dolor se experimentaba como alegría, al tiempo que una sensación de supremo triunfo arrancaba gritos de angustia del corazón. Desde ahora, en cada alegría exuberante se oirá un trasfondo de terror" (Franz 2005: 225).

$6 \quad$ Es decir, con la problemática del sufrimiento, del Mal gratuito que aun Dios puede decidir infligir.

7 Reproducimos las letras cursivas presentes en los capítulos de la narración retrospectiva (el pasado de Laura durante la Dictadura Chilena).
} 
“[...] la fusión de las antípodas, la unión inseparable del amor y del horror" (Citado en Sarduy 1987: 236). En efecto, considera al erotismo como una forma sagrada, es decir, respecto a la cual tenemos a la vez un sentimiento de fascinación y de horror, o sea, una mística de la sexualidad (Bataille 2005). Entonces, aquí, a diferencia de la víctima, el mártir masoquista acepta el dolor y casi lo provoca, reconociéndolo como una forma de acercamiento a su amo. Pero, el mártir, en este sentido, ¿no alcanzaría a tener un propio poder sobre el torturador? Tomamos el ejemplo de la película Año Bisiesto de Michael Rowe (2010), donde la protagonista toma la iniciativa en la relación sado-masoquista, provocando a su doble sádico a fin de actuar. Al final de la película, la mujer pide a su amo matarla, lo que el hombre no alcanzará a realizar, dejándola en el último y en el peor de los sufrimientos: la supervivencia.

Si el mártir se define en relación con el dolor, la etimología primera es la de "testigo". Así, si las obras invierten la primera significación del término, crean también una nueva dimensión del mártir como testigo, en paralelo con la figura contemporánea del mártir, es decir, del mártir de un ideal en general.

\section{De LA RECREACIÓN DEL MÁRTIR COMO TESTIGO}

Las dos obras de nuestro corpus de análisis invierten la figura tradicional del mártir, pero a fin de adaptar y recrear, a partir de una deformación y de una desviación, la figura del mártir como testigo. En efecto, la segunda acepción del término "mártir" es la de testigo: "El testigo es capaz de sufrir y morir por lo que cree. Cuando la prueba de la convicción llega a ser el precio de la vida, el testigo cambia de nombre: se llama mártir. [...] en griego, quiere decir testigo" (Ricoeur 1983: 21).

Por ejemplo, en la película Martyrs de Pascal Laugier (2008), una mujer se encuentra rehén de una secta, cuya meta es transformar humanos "ordinarios" en mártires a través del sufrimiento, de la tortura, a fin de alcanzar un estado de éxtasis más allá de la frontera entre la muerte y la vida, permitiendo revelar el destino del hombre después de la muerte. En este sentido, el mártir puede constituirse como testigo de una época y de un ideal correspondiéndolo (por ejemplo, la figura del resistente) y/o de una experiencia suprasensible (el poder de la fe, la vida después de la muerte, etc.).

En las dos obras del corpus, tenemos la figura del mártir "resistente", es decir, una transformación del mártir cristiano, respecto a una redefinición contemporánea, con el mártir luchando en general por un ideal, a partir de la fe religiosa reemplazada por la "fe revolucionaria". En efecto, la protagonista de La vida doble es una activista de un movimiento revolucionario, mientras que la del Desierto es una jueza, tratando de establecer una justicia "justa" en contra de los militares ${ }^{8}$.

Primero, en La vida doble tenemos una diferenciación entre el mártir y la figura del héroe. El mártir sería la parte obscura del héroe, es decir, aceptando el sufrimiento, el dolor y la culpabilidad inherente a la condición humana. En este sentido, no se trata para el mártir de una problemática de victoria sobre la autoridad, al contrario del héroe, figura mítica colectiva del triunfo. El héroe del relato es Canelo que decidió, al contrario de la protagonista, morir en vez de la captura, de la tortura y de la colaboración: "La obra de su vida fue su muerte. Ser héroe es eso" (135).

Además, las dos protagonistas se presentan, mediante un relato en la primera persona, como testigo de la Historia y de su propia historia. 
A continuación y como lo dijimos, la figura del mártir cristiano y del mártir de un ideal (el resistente), se mezclan continuamente en la obra, con un uso del campo lexical religioso aplicado a la lucha política. En efecto, Irene describe su compromiso político de la manera siguiente: "Así fue mi rito de iniciación [...] tú comprendes, pertenecer a esta familia secreta y prohibida y elegida por mí era nacer de nuevo y estar dispuesta al sacrificio" (Fontaine 2010: 74).

Además, cuando se refiere a los militares, habla de "tentación" (76) y la lucha política es asimilable a la religión, respecto a un fanatismo: “¿Un Cristo, entonces, revolucionario, masón, y ateo, devoto del "materialismo histórico [...]?" (123).9

Al mismo tiempo, la dimensión testimonial del mártir es claramente evocada: “Queríamos sólo dar testimonio. Éramos profetas y nostálgicos, no políticos con futuro. Y, por supuesto, nuestro camino armado era "inviable"" (Fontaine 2010: 132). Sin embargo, sucede la etapa de la desilusión (con la muerte de Canelo, su propia colaboración, etc.), subvirtiendo la imagen del resistente y del héroe glorioso: "Héroes transformados en víctimas; en lugar del honor, el lamento y la compasión; en lugar de leones, corderos" (127). Encontramos una vez más (todavía en La vida doble), la propia subversión del campo lexical religioso, aplicado a la lucha política: "[...] la Historia era algo así como un largo peregrinaje colectivo y redentor, un duro y tortuoso Purgatorio que conducía al Paraíso" (136).

Podemos también dar el ejemplo de la comparación, respecto a la desilusión general, con la pérdida del Paraíso Terrenal y con el nacimiento de la culpabilidad colectiva: “[...] somos animales carnívoros mal disfrazados y sin inocencia. Eso fue lo que perdimos en el Paraíso: La inocencia animal. Nos miramos desnudos y nació la vergüenza. El infierno es un espejo del que no puedes apartar la vista" (Fontaine 2010: 206).

En El Desierto, tenemos la figura del chivo expiatorio ${ }^{10}$, es decir, Laura va a entregarse al militar Cáceres a fin de salvar su ciudad y detener las ejecuciones. En este sentido, la protagonista es asimilada a la Patrona de la ciudad: "Se parecen, Laura: Ios dos jovencitas, bellas, con una responsabilidad tan grande. $Y$ tan dispuesta a sufrir por ella" (57). Entonces, representa también un símbolo de la culpabilidad colectiva (y de su problematización) de la ciudad por su colaboración con los militares ${ }^{11}$ : "La dictadura fue total y el pueblo estuvo justificado al no resistir ese poder total" (309). "Si la dictadura fue total, la obediencia individual fue legítima" (310).

Así, parece que la violencia del periodo de la Dictadura es desviada hacia la figura del chivo expiatorio, lo que plantea, además, la pregunta de la fuente de la violencia; en efecto, ¿no sería la comunidad que quiere protegerse, mediante el sacrificio, de su propia violencia? En todos los casos, el sacrificio aparece aquí como un proceso social.

Cabe notar también que la historia se desarrolla durante un carnaval religioso, lo que según Bajtín, corresponde al espacio privilegiado de la expresión de lo prohibido,

\footnotetext{
$9 \quad$ Por supuesto, con la asimilación al mártir supremo: Jesús Cristo.

10 "Chivo expiatorio denota simultáneamente la inocencia de las víctimas, la polarización colectiva que se produce contra ellas y la finalidad colectiva de esta polarización" (Girard 2002: 56-57).

11 "Si toda la nación está convencida de perecer, es mejor sin duda que muera un hombre por todos los demás" (Girard 2002: 151).
} 
o sea, un momento de suspensión de las leyes sociales. La temática del carnaval se une entonces a la del chivo expiatorio ${ }^{12}$ : "[...] durante toda la fiesta los peregrinos viejos, los penitentes más antiguos, los diablos caporales, buscaban al diablo para ayudarlo a hacer su sacrificio. Pues sólo cuando sacrificaran al diablo verdadero, los demás podrían estar seguros de que eran inocentes" (Franz 2005: 167).

En efecto, la palabra "carnaval" proviene de "carnelevare", es decir, compuesta por "carne" y "levare" (quitar), lo que podría ser entendido como la extracción de la carne y en este contexto, la del chivo expiatorio, mediante su sacrificio.

Además, como en La vida doble, encontramos el campo lexical religioso subvertido y aplicado a la situación de la Dictadura Militar: “¿Cuál pasaje de la Biblia es ese donde un ángel ofrece salvar a una ciudad, si alguien es capaz de encontrar diez justos en ella?" (216).

Por ejemplo, la protagonista es descrita como "nuestra ministra de fe" (133) y su tortura es asimilable a un "ceremonial" (264).

Si se opera en La vida doble una reflexión sobre el papel del resistente, El Desierto plantea la problemática de la aplicación de la justicia en el mundo del Mal (la Dictadura Militar), a la manera una vez más, de la reflexión del Libro de Job: “[...] ¿sería capaz de hacer justicia en los tiempos de voluntad que se indicaban?" (32).

Es decir que se plantea la diferencia entre lo legal y lo justo y la problemática de la aceptación de la presencia ineluctable del Mal: "El bien y el mal ya no lucharían entre sí; se sentarían a la misma mesa y pesarían sus intereses. Nuevos tiempos que requerían nuevos jueces [...] era terrible pactar y era necesario pactar con lo terrible" (Franz 2005: 282).

Entonces, las dos novelas dan una nueva dimensión al mártir como testigo, creando la figura del mártir contemporáneo, es decir, al servicio de la lucha por un ideal. Pero, una vez más, invierten esta imagen con la figura de la colaboradora, de la caída del héroe y también de la realidad del chivo expiatorio, destinado a limpiar la culpabilidad colectiva de la comunidad.

La vida doble de Arturo Fontaine y El Desierto de Carlos Franz invierten la imagen del mártir como el que sufre mediante el fenómeno del sado-masoquismo y crean un nuevo tipo de mártir-testigo, como persona luchando por un ideal. Sin embargo, van más allá, subvirtiendo esta última imagen, con la derrota de los ideales en general, respecto a la presencia ineludible e inclemente del Mal. Tratamos ahora de seguir esta nueva huella, hacia la aprehensión de todas sus implicaciones.

\section{De LA HUELLA DEL MÁRTIR}

Como lo dijimos, el mártir es un testigo en relación, entonces, con la expresión de una época particular, es decir, el mártir se inscribe como figura revelando, mediante su historia, la Historia. Por tanto, el mártir podría también constituirse como una figura de predilección (lo que se verifica respecto a nuestro corpus de estudio) de la literatura postdictatorial, buscando, al contrario del intento para blanquear el pasado,

12. "La función de la fiesta no es diferente de la de los restantes ritos sacrificiales. Como ha entendido muy bien Durkheim, se trata de vivificar y renovar el orden cultural repitiendo la experiencia fundadora, reproduciendo un origen que es percibido como la fuente de toda vitalidad y de toda fecundidad: es en aquel momento, en efecto, cuando la unidad de la comunidad es más estrecha, y el temor de recaer en la violencia interminable más intenso" (Girard 1995: 28). 
enfrentarse con él y con su horror: "[...] la literatura postdictatorial lleva consigo las semillas de una energía mesiánica que, como el ángel benjaminiano de la historia, mira hacia el pasado, a la pila de escombros, ruinas y derrotas, en un esfuerzo por redimirlos, mientras es empujado hacia adelante por las fuerzas del "progreso" y la "modernización" (Avelar 2000: 286).

De ese modo, el mártir se constituye también como una figura violenta o más bien que acepta y expresa el sufrimiento latente de un periodo ${ }^{13}$. En este sentido, ¿podemos decir que la emergencia de un mártir se gesta en paralelo con un contexto violento? ¿Cuál es la relación entre la creación del mártir y un contexto histórico? Por ejemplo, vimos en El Desierto la figura del chivo expiatorio como cristalización individual de la culpa colectiva de una ciudad que "colaboró" durante la Dictadura Militar. Además, a un nivel más contextual, el mártir sigue el mismo procedimiento que la Dictadura Militar, es decir, que una cosa que debería "salvarme" (la fe en general o el Estado garantizando mi seguridad y mi libertad), en realidad, me mata.

Lo que parece cierto es que el mártir es una figura de subversión. Primero, respecto a la etimología de "subversión", es decir, un movimiento que proviene de abajo, por lo tanto, popular por esencia. Este movimiento se inscribe en contra del movimiento de arriba, o sea, de la autoridad, del orden establecido y constituye entonces, un acta de resistencia:14 "El testigo es el hombre que se identifica con la causa justa, odiada por la muchedumbre y los grandes y por esta causa justa arriesga su vida" (Ricoeur 1983: 22).

En las obras de nuestro corpus de análisis, por medio de la deformación de la imagen convencional del mártir, encontramos también una reflexión sobre la posición histórica del mártir. En efecto, en La vida doble, asistimos a la elaboración de una poética de la novela y del testimonio: "Nadie puede comprender esta historia [...]. Quedará la fábula edificante con su moraleja, quedará la cáscara de los hechos, la pornografía del horror. Eso ya se sabe. Pero lo que les dio un sentido, lo que los hizo humanos, muere con nosotros" (39).

Además, después de la pintura de los resistentes gloriosos de la Dictadura Militar, encontramos en las dos novelas, la presentación de una anti-figura, con la imagen de una mujer colaborando hasta enamorarse de su torturador e, incluso, tener un hijo con él. Es decir que empedremos una nueva huella, más obscura, lejos de la mera dicotomía entre el Bien y el Mal: "Pero al final buscas una aventura moral [...]. La verdad es demasiado inquietante, espinuda, contradictoria y espantosa. La verdad es inmoral. No debe imprimirse. Tú no escribirás lo que te cuente" (Fontaine 2010: 39).

Parece, entonces, que la creación de una nueva figura del mártir acompaña, aquí, una nueva percepción de la Historia y de la memoria en general: se acabó el tiempo de los relatos ejemplares de los héroes de la nación; entramos en algo diferente, al considerar a esta subjetividad incierta y sufrida, más cerca del Mal y de lo abyecto, como entonces, espejo particular de un contexto violento y ambiguo: "Lo que hace un hombre es como si lo hicieran todos los hombres. Jorge Luis Borges" (Fontaine 2010: 9).

En este sentido, el camino de fe de nuestros mártires se acerca lógicamente a un camino identitario, pero una vez más, desviado, mediante, por ejemplo, el fenómeno

\footnotetext{
"La nación chilena es a su dictador lo que la Flaca Alejandra a su torturador: hembras golpeadas y humilladas pero que soportan enamoradas la bota que la pisotea mientras gimen lastimeros refranes de venganza" (Devés 1996: 103).

14 Y encontramos de nuevo aquí, la figura más moderna y más política de la figura del mártir.
} 
del sado-masoquismo, o sea, el intento de encontrarse a sí mismo en la humillación y en el sufrimiento. Por ejemplo, en La vida doble, Irene se aproxima una vez más a la figura humilde y dolorosa del mártir, a partir de un cuestionamiento y de un desdoblamiento identitario: "La torturada, me creí la torturada heroica, la prisionera política que había sobrevivido, la víctima. ¿Pero me lo creía realmente?” (85).

En El Desierto, el proceso llega hacia una esquizofrenia identitaria: "La imagen de la que soy y la que fui luchan por imponerse la una a la otra, se alternan y finalmente gana el pasado" (28).

Para resumir, se establece una dialéctica cuerpo-identidad que aparece como un proceso inestable y adaptable, respecto a un Ser-mujer enfrentándose con la autoridad que quiere mantenerse a través de la violencia y a partir de la destrucción del sujeto.

Así, parece que la figura del mártir que tratamos de esbozar se mezcla con la de la víctima, respecto a la noción de placer al interior de un proceso identitario. En efecto, en tanto a una visión más contemporánea y como testigo de una época, el mártir parece ser, ante todo, una figura ideológica y, a partir de esto, una subjetividad entera y unida consigo misma, aceptando pagar con su vida, su fe en sus ideales. Por su parte, la víctima conserva su instinto de supervivencia y así se somete, al contrario del mártir, a fin de sobrevivir. Sometiéndose, acepta como lo vimos en los ejemplos anteriores, denegar su identidad y emprender una reconfiguración identitaria, no obstante, al seno de una esquizofrenia identitaria (la identidad de "la que es" y de "la que fue" en la cita anterior del Desierto). Se somete, además, a la tortura y al placer que puede encontrar el sadista en esta relación de sumisión/dominación. En este sentido, habría que diferenciar el placer en la sumisión y sin alternativa de la víctima y el placer del mártir en la tortura, haciendo parte de su camino redentor. O sea, las dos figuras emprenden un camino identitario, pero se diferencian respecto a la reconfiguración identitaria forzada de la víctima y a la persistencia del Ser del mártir al interior de su ideología. Además, encuentran su placer en el dolor, pero una vez más, respecto a una discrepancia en tanto a una aceptación voluntaria/involuntaria del suplicio. Parece así que las dos protagonistas del corpus se configuran como mártires a partir de la aceptación del sufrimiento, y a la vez, como víctimas, respecto al emprendimiento de una reconfiguración identitaria.

No obstante, se trata únicamente de mujeres que siguen esta huella y que adquieren el estatus de mártir en las dos novelas. En la tradición cristiana, la mujer mártir (y lógicamente virgen) se presenta con frecuencia como una mujer linda y codiciaba por un hombre importante (símbolo de la autoridad) (Vigarello 2005). Pero, en varios casos, la mujer desdeña la proposición de matrimonio del hombre, considerada como contraria a su fe y a su amor por Dios (el hombre inscribiéndose en contra de su creencia). Así, tenemos el ejemplo de Santa Agatha de Catania quien se cortó sus senos (como símbolo de feminidad y con el cuerpo como lugar del pecado/salvación) o Santa Lucía de Siracusa quien se mutiló, sacándose sus ojos.

En La vida doble y en El Desierto, a través del sado-masoquismo, tenemos una mujer que va a ir hacia lo más profundo del horror, es decir, el enamoramiento de su torturador y hasta tratar de encontrar en la sumisión y en el sufrimiento, una posibilidad de aceptación y quizás, de liberación. Una novela pertinente respecto a este asunto, sería Histoire d'O de Pauline Réage. Estamos aquí en presencia de una ascética del amor, de una Justine voluntaria que decide amar hasta morir y encontrar su libertad como esclava. La figura del mártir está por supuesto aquí, en una mujer que soporta la tortura a partir de una devoción amorosa y casi sagrada. 
Por otro lado, tenemos también el ejemplo del hombre esclavo-mártir de una mujer ${ }^{15}$, figura con la que sería sumamente interesante establecer una comparación con su doble femenino. Por ejemplo, en su cuento "Putas Asesinas", Roberto Bolaño invierte el cuento de hadas, con una mujer sádica secuestrando y torturando al príncipe de sus sueños: "Sólo sé que por fin nos hemos encontrado, y que tú eres el príncipe vehemente y yo soy la princesa inclemente" (2001: 128). Sin embargo, el ejemplo más famoso sería la obra de Sacher-Masoch y sobre todo, La Vénus à la fourrure. Se trata casi del lado masculino de Histoire d'O, con un hombre entregándose totalmente a una mujer déspota, hasta convertirse en su esclavo. De todos modos, en los dos casos (la figura femenina y la masculina del mártir), nos encontramos de nuevo con el concepto de abyección, pero esta vez aplicado a los estudios de género, a fin de describir este lugar al límite, de los seres ajenos al discurso hegemónico:

Lo abyecto designa aquí precisamente aquellas zonas "invisibles", "inhabitables" de la vida social que, sin embargo, están densamente pobladas por quienes no gozan de la jerarquía de los sujetos, pero cuya condición de vivir bajo el signo de lo "invisible" es necesaria para circunscribir la esfera de los sujetos. Esta zona de inhabitabilidad constituirá el límite que defina el terreno del sujeto; constituirá ese sitio de identificaciones temidas contra las cuales $-\mathrm{y}$ en virtud de las cuales- el terreno del sujeto circunscribirá su propia pretensión a la autonomía y a la vida (Butler 2002: 20).

En este sentido, la elección del destino de mártir por las subjetividades convierte el proceso de sumisión en resistencia (Reik 1963). O, en otras palabras, "Aunque no existe una relación directa entre los vínculos donde se producen los deseos y el lugar donde son confirmados, como bien lo concluye Butler, el lugar del sometimiento, como lugar del dolor y de la capacidad del deseo, es el lugar de la resistencia" (Femenías 2003: 103).

Eso plantearía finalmente la pregunta de la configuración de las identidades dentro de un contexto violento, con la figura del mártir como punto de partida de una reflexión más amplia.

\section{CONCLUSIÓN}

Como lo esbozamos en la introducción de este estudio, la belleza de la figura del mártir reside en la entrega de sí mismo sin límite y sin compromiso. Es también una figura prometeana, con una elevación transcendental posible a partir de una caída voluntaria. En un registro más psicoanalítico, provoca el encuentro de Eros y de Tánatos, acercándose inevitablemente a la muerte, pero sobre todo, a una idea sagrada del amor. A partir de esta perspectiva, ¿estaríamos aptos para entender el ultraje voluntario de la protagonista de Histoire d'O, ya que ante todo es prueba de amor? Es la huella contemporánea, encarnada y turbia del mártir que queríamos considerar en nuestro análisis, a partir de la comparación de dos novelas chilenas: $L a$ vida doble de Arturo Fontaine y El Desierto de Carlos Franz.

15 Acordándose que Von Krafft-Ebing, en Psychopatia Sexualis, avec recherches spéciales sur l'inversion sexuelle (1895), definía de una manera singular el sadismo del hombre como natural y el masoquismo como una perversión exclusivamente femenina. 
Primero, las dos obras parecen invertir la figura del mártir como el que sufre, respecto al sado-masoquismo y/o al síndrome de Estocolmo. El mártir se convierte pues en un masoquista y se acerca a la figura de la autoridad (el torturador), hasta emprender una relación de amor con él. A partir de esta adhesión a la dominación y del establecimiento de una "intimidad", el mártir casi invierte los papeles, con una forma de poder sobre su amo. En El Desierto como en Carne de Perra de Fátima Sime (2009), es el torturador que al final de la novela, pide a su mártir darle la muerte. Esto plantaría entonces la pregunta del mártir, dentro de la relación sado-masoquista, como propio agente de su transformación.

Segundo, las dos obras crean un nuevo tipo de mártir, a partir de la transformación de la imagen tradicional del testigo de la fe cristiana. En efecto, estamos en presencia de la figura del resistente en La vida doble y del chivo expiatorio en El Desierto. Respecto a esta adaptación del estereotipo, asistimos a un uso del léxico religioso, pero aplicado, por ejemplo, a la "fe revolucionaria" o a la relación entre el mártir y su verdugo, concebido como un dios. Sin embargo, las novelas van más allá y describen también la caída de este nuevo tipo de mártir, en La vida doble, con la pérdida de los ideales revolucionarios y, en El Desierto, con la descripción de la realidad de un chivo expiatorio, opuesta a una gloria salvadora y deliberadamente sacrificial.

Finalmente, esbozamos las implicaciones de la reconsideración actual del mártir en la literatura. En principio, el mártir constituye el medio de una lectura subversiva de la Historia, es decir, considerando a su lado turbio, como con la figura de la colaboradora, ya no traidora suprema, pero subjetividad encarcelada en la ambigüedad de su propia historia. Además, con la consideración de figuras exclusivamente femeninas, la mártir podría organizar una nueva perspectiva respecto a los estudios de género. Luego, nos parece que estas dos novelas emprenden la huella que todavía falta, es decir, el relato verdadero y profundo del horror de la Dictadura Chilena.

Así, el mártir como figura literaria, a través de su reapropiación, de su inversión y de su recreación, permanece como un medio válido, fuerte y sutil de aproximación a nuestra "realidad"16. En efecto, en el sentido del concepto de "transgresión" de Bataille (y de Foucault también), el mártir está siempre en marcha, siempre al borde, manteniendo y yendo más allá de los límites, a fin de enfrentarse con lo prohibido, el horror y, a la vez, con lo sublime, a través del discurso. En otras palabras, el mártir parece luchar en contra de sí mismo a fin de buscar su propia condición para ser. Así, la desviación de los mecanismos de representación literaria del mártir, permite poner en cuestión las normas y densificar los modos de aprensión de una ideología. Sería quizás interesante, en este sentido, extender nuestro análisis a la subversión de otras categorías subjetivas históricas, pensando en la del héroe, o sea, estudiar los procesos de inversión del salvador glorioso de la nación ${ }^{17}$ o relacionar las dos subjetividades femeninas de nuestro estudio, con la figura exclusivamente hispano-americana de la Malinche.

Justamente, a la manera de una literatura antropológica, el mártir ofrece una concepción del hombre, de la cultura y de la naturaleza al interior de su subversión; se trata de una nueva forma a fin de sentir y pensar: el mártir se convertiría en un monstruo semiológico. Así, el nuevo mártir, entre lucha, violencia y sumisión, nos ofrece una

\footnotetext{
${ }_{16}$ A partir de una literatura considerada como una investigación imaginaria de lo posible.

17 Considerando al mártir como una categoría del antihéroe.
} 
multiplicidad de nuevas huellas a emprender. Se trataría solamente de aceptar el camino obscuro, afuera de los límites y sin concesión de este nuevo mártir. Entonces, todo dependerá de la persona que quiere caminar y seguir estas huellas más tiempo...

\section{OBRAS CITADAS}

Avelar, Idelber. 2000. Alegorías de la derrota: la ficción postdictatorial y el trabajo del duelo. Chile: Editorial Cuarto Propio.

Bolaño, Roberto. 2001. Putas asesinas. "Putas Asesinas”. España: Editorial Anagrama. 113-129.

Bataille, Georges. 2005. El erotismo. Trad. de Antoni Vicens y Marie Paul Sarazin. España: 34 Ensayo, Tusquets Editores.

Bourdieu, Pierre. 2000. La dominación masculina. Trad. de Joaquín Jordá. España: Editorial Anagrama.

Butler, Judith. 2002. Cuerpos que importan. Sobre los límites materiales y discursivos del "sexo". Argentina: Paidós.

Deleuze, Gilles. 2007. Présentation de Sacher-Masoch, "Le Froid et le Cruel", avec le texte intégral de La Vénus à la Fourrure. Trad. par Aude Willm. France: Éd. de Minuit, Col. Arguments.

Devés, Eduardo. 1996. "Entre el machismo y el sadomasoquismo. Una visión del género en Chile" (97-107). En Diálogos sobre el género masculino en Chile. Sonia Montecino y María Elena Acuña, Comp. Chile: Universidad de Chile, Facultad de Ciencias Sociales, Programa interdisciplinario de estudios de género.

Eltit, Diamela. Octubre 1996. "Cuerpos nómadas". Debate Femenista 14: 101-117.

Femenías, María Luisa. 2003. Judith Butler: introducción a su lectura. Argentina: Catálogos. Fontaine, Arturo. 2010. La vida doble. Argentina: Tusquets Editores, Col. Andanzas.

Franz, Carlos. 2005. El desierto. Argentina: Editorial Sudamericana.

Girard, René. 2002. El chivo expiatorio. Trad. de Joaquín Jordá. España: Editorial Anagrama. .1995. La violencia y lo sagrado. Trad. de Joaquín Jordá. España: Editorial Anagrama.

Havelock, Ellis. 1921. Études de psychologie sexuelle. Tome III. Éd. française, revue et augmentée par l'auteur. Trad. de A. Van Genrep. France: Mercure de France.

Hegel, G. W. F. 2000. Fenomenología del espíritu. Trad. de Wenceslao Roces, con la colaboración de Ricardo Guerra. España: Fondo de Cultura Económica.

Kristeva, Julia. 1988. Poderes de la perversión. Ensayo sobre F. Céline. Trad. de Nicolás Rosa y Viviana Ackerman. Argentina: Catálogo Editora.

Laugier, Pascal. 2008. Martyrs. France-Canada: Canal +, Eskwad, Wild Bunch.

Réage, Pauline. 2009. Histoire d'O, suivie de Retour à Roissy. France: prologue de Jean Paulhan, appendice de Pieyre De Mandiargues, Éd. Pauvert.

Reik, Theodor. 1963. Masoquismo en el hombre moderno. Vol. 1 y 2. Argentina: Ed. Sur, Col. Ensayos.

Ricoeur, Paul. 1983. Texto, Testimonio y Narración. Traducción, prólogo y notas de Victoria Undurraga. Chile: Editorial Andrés Bello.

Rowe, Michael. 2010. Año Bisiesto. México: Golem.

Sarduy, Severo. 1987. Ensayos Generales sobre el Barroco. Argentina: FCE.

Sime, Fátima. 2009. Carne de Perra. Chile: Ed. LOM.

Vigarello, G. 2005. Historia del cuerpo. Vol. 1: "Del renacimiento al Siglo de las Luces" y vol. 2: "De la Revolución Francesa a la Gran Guerra". Bajo la dirección de Alain Corbin, Jean-Jacques Courtine, Georges Vigarello. Trad. de Núria Petit y Mónica Rubio. España: Taurus Historia.

Von Krafft-Ebing, Richard. 1895. Psychopatia Sexualis, avec recherches spéciales sur l'inversion sexuelle. Trad. de E. Laurent y S. Caspo. France: Masson and Cie Editeurs. 
